\title{
Article \\ Characterization of Aluminum Alloy-Silicon Carbide Functionally Graded Materials Developed by Centrifugal Casting Process
}

\author{
Ioan Milosan ${ }^{1} \mathbb{D}$, Tibor Bedő ${ }^{1, *(\mathbb{D})}$, Camelia Gabor ${ }^{1}\left(\mathbb{D}\right.$, Daniel Munteanu ${ }^{1}$, Mihai Alin Pop ${ }^{1}\left(\mathbb{D}\right.$, Dorin $^{\text {Catana }}{ }^{2} \mathbb{D}$, \\ Mihaela Cosnita ${ }^{3}$ and Béla Varga ${ }^{1}$
}

1 Materials Science Department, Faculty of Materials Science and Engineering, Transilvania University of Brasov, 29 Eroilor Bld., 500036 Brasov, Romania; milosan@unitbv.ro (I.M.); camelia.gabor@unitbv.ro (C.G.); danielmunteanu@unitbv.ro (D.M.); mihai.pop@unitbv.ro (M.A.P.); varga.b@unitbv.ro (B.V.)

2 Materials Engineering and Welding Department, Faculty of Materials Science and Engineering, Transilvania University of Brasov, 29 Eroilor Bld., 500036 Brasov, Romania; catana.dorin@unitbv.ro

3 Department of Product Design, Mechatronics and Environment, Faculty of Product Design and Environment, Transilvania University of Brasov, Colina Universitatii Street, no. 1, 500068 Brasov, Romania; mihaela.cosnita@unitbv.ro

* Correspondence: bedo.tibor@unitbv.ro; Tel.: +40-770667583

\section{check for} updates

Citation: Milosan, I.; Bedő, T.; Gabor C.; Munteanu, D.; Pop, M.A.; Catana,

D.; Cosnita, M.; Varga, B.

Characterization of Aluminum

Alloy-Silicon Carbide Functionally Graded Materials Developed by Centrifugal Casting Process. Appl. Sci. 2021, 11, 1625. https://doi.org/ 10.3390/app11041625

Academic Editor:

Francesco Tornabene

Received: 19 January 2021

Accepted: 8 February 2021

Published: 11 February 2021

Publisher's Note: MDPI stays neutral with regard to jurisdictional claims in published maps and institutional affiliations.

Copyright: (C) 2021 by the authors. Licensee MDPI, Basel, Switzerland. This article is an open access article distributed under the terms and conditions of the Creative Commons Attribution (CC BY) license (https:// creativecommons.org/licenses/by/ $4.0 /)$.
Abstract: The continuous development of modern industries rises the necessity for functionally graded materials. This research starts from the consideration that the incorporation of SiC particles in the molten aluminum alloy can be difficult due to the very low wettability of SiC particles. In order to increase their wettability, $\mathrm{SiC}$ particles were covered with a layer of metallic copper. The incorporation of $\mathrm{SiC}$ particles into the aluminum alloy mass was performed by centrifugal casting. The secondary hypoeutectic Al-Si alloy used in this study was elaborated within the crucible of a resistors heated furnace. The metallic coating of $\mathrm{SiC}$ particles, in addition to the effect of increasing their wettability by molten metal, also has a role in preventing the formation of aluminum carbide in case of heating above $700{ }^{\circ} \mathrm{C}$. A great amount of attention was paid to the parameters used during the centrifugal casting process. The results showed that adjusting the proportion of SiC particles within the composite allows us to obtain values of the thermal expansion coefficient within previously established limits. The present work demonstrates that the coating of $\mathrm{SiC}$ particles covered with a thin layer of metallic $\mathrm{Cu}$ creates the conditions to easily incorporate them into the molten $\mathrm{Al}$ mass, thus obtaining FGMs with controlled properties.

Keywords: functionally graded materials; aluminum alloy-SiC composites; copper films; centrifugal casting

\section{Introduction}

The alert pace in which technology develops nowadays leads us with no doubt to what the researchers named "Industry 4.0". This stage of industry development is not possible without the astonishing development of materials engineering research. Considering the growing importance that nowadays is given to Industry 4.0, obtaining functionally graded materials (FGMs) becomes vital. It should be kept in mind that functional structures with a gradient of properties are found in nature (for example in animal tissues). These structures have a high wear resistance at the exterior at the same time as a ductile interior.

There are almost no areas of technology where new materials are not needed. The need to develop property gradient materials has arisen with the development of modern industries that are increasingly demanding products that behave differently depending on the demands [1]. Based on these considerations, in 1984, in Japan, the concept of FGM first appeared. A large number of researchers have turned their attention to FGMs. Some 
of them focused on the analysis of the production process of these materials as well as on the modelling and simulation of the process [2-6] while others turned their attention to the inevitably generated residual stresses of FGMs due to thermal mismatch of each basic material using experimental and analytical methods [7,8] or their characterization [1]. Over time, a number of techniques have been developed in order to obtain FGMs: Powder metallurgy, vapor deposition, solid free form fabrication, centrifugal casting, and additive manufacturing $[9,10]$.

In the large family of new developed materials, composites materials play an important role nowadays. Taking into account that an assembly of two or more materials with completely different properties leads to a composite with superior properties surpassing those of each component basic material, we realize why significant amounts are invested in researching these materials. Precisely for this improvement in terms of properties when compared to those of each component, these materials have special applications, for example in the aerospace industry [11-13], in the biomedical industry as well as in other engineering applications that require new materials with superior properties.

Composites of aluminum metallic matrix with various types of reinforcers already show a wide spread in various industries, such as automotive, aviation, military, etc. Al matrix reinforced with $\mathrm{SiC}$ composite materials are of great interest especially for the automotive industry [14-22]. Compared to aluminum alloys, they have superior properties such as high strength, high fatigue strength, high specific modulus, and high hardness. Due to the high thermal conductivity $\left(180-200 \mathrm{~W} \cdot \mathrm{m}^{-1} \mathrm{~K}^{-1}\right)$ they can be successfully used as thermal radiators in the electronics industry.

A large number of research from prestigious universities and/or research institutes has been conducted in the study of aluminum alloy composites reinforced with $\mathrm{SiC}$ particles [17,22-24]. However, the actual published data are limited regarding the obtaining process, while most articles deal with specific properties of the composites. Most researchers reported the use of the stirring-casting method to incorporate $\mathrm{SiC}$ particles [25]. Therefore, deficiencies were encountered due to the fact that $\mathrm{SiC}$ particles cannot be moistened by the aluminum alloy. With copper being one of the elements almost perfectly wetted by aluminum, a number of articles refer to the coating of $\mathrm{SiC}$ particles with a thin layer of copper leading to a correct wetting by the aluminum alloy $[14,26,27]$.

Increasing the wettability of $\mathrm{SiC}$ particles by coating them with $\mathrm{Cu}$ films could be an important factor in increasing the cohesion between the metal matrix and the reinforcing material when producing aluminum-based composites [24,28-31].

Based on these considerations, the present research aims to describe the process of incorporation of the free $\mathrm{SiC}$ particles (coated with $\mathrm{Cu}$ ) into the basic metallic mass (aluminum alloy). Beside the non-wetting phenomenon, the resistance of the aluminum oxide layer also occurs during the embedment of the $\mathrm{SiC}$ particles. In order to overcome this difficulty, the use of centrifugal casting (with vertical rotation axis in this case) is proposed. It should be emphasized that the present research continues the previous ones in this field [24].

The use of centrifugal casting in the processing of metal matrix composites (MMC) with aluminum matrix and ceramic reinforcing elements $\left(\mathrm{Al}_{2} \mathrm{O}_{3}, \mathrm{SiC}, \mathrm{TiB}_{2}\right.$, etc.) is analyzed by several researchers [32-35].

Production of FGMs using centrifugal casting involves two types of procedures: Exsitu FGM and in-situ FGM. Ex-situ processing involves the previous synthesis of the metal matrix composite (MMC) by the stirring casting method [36] followed by the casting of the composite slurry in the centrifugal casting unit. During the in-situ processing, the reinforcement is added to the base metal mass directly in the shell of the centrifugal casting system in which the liquid alloy of the metal matrix is already present. The in-situ method was also used in this paper.

The samples were analyzed by means of metallographic analysis (MA), X-ray diffraction analysis (XRD), scanning electron microscopy (SEM), dilatometric analysis (DIL) and differential thermal analysis (DTA). 
Considering the literature background, the present research shows how the coating of $\mathrm{SiC}$ particles with a thin layer of metallic $\mathrm{Cu}$ essentially influences their incorporation into the molten aluminum alloy metal mass. By now, the most frequently reported method applied by other researchers was stirring casting, while this paper is focused on the use of centrifugal casting in the in-situ configuration and on the emerging advantages in obtaining FGMs. Furthermore, by means of thermal analysis, the authors aimed to demonstrate that the coefficient of thermal expansion of these $\mathrm{Al}-\mathrm{SiC}$ composites can be controlled by varying the proportion of $\mathrm{SiC}$.

\section{Experimental Details}

\subsection{Materials}

For the present research, a secondary hipoeuthectic Al-Si alloy with a high iron content was chosen as a base metal to be pressure casting. The chemical analysis performed with a Spectromax XF-BT spectrometer is presented in Table 1.

Table 1. Chemical composition of the Al-Si alloy.

\begin{tabular}{cccccccccc}
\hline Element & $\mathbf{S i}$ & $\mathbf{F e}$ & $\mathbf{C u}$ & $\mathbf{M n}$ & $\mathbf{M g}$ & $\mathbf{Z n}$ & $\mathbf{T i}$ & $\mathbf{P b}$ & $\mathbf{A l}$ \\
\hline$[\%]$ & 8,23 & 1,50 & 0,117 & 0,111 & 0,062 & 0,166 & 0,022 & 0,014 & 89,70 \\
\hline \multicolumn{10}{c}{ The sum of the elements is not $100 \%$ since the composition includes elements with very } \\
low concentrations.
\end{tabular}

The silicon carbide powder used in this research was superfine (600 grit) with an average grain size of $137 \mu \mathrm{m}$ and a $3.16 \mathrm{~g} \cdot \mathrm{cm}^{-3}$ density, provided by Alfa Aesar $\mathrm{GmbH}$, Kandel, Germany.

In order to increase the wettability of the $\mathrm{SiC}$ particles in AlSi alloy the particles were covered with a $\mathrm{Cu}$ film (treated $\mathrm{SiC}$ ) using a coating solution with the following composition: Distilled water, copper sulphate $\left(\mathrm{CuSO}_{4}\right)$, sodium hydroxide $(\mathrm{NaOH})$, sodium and potassium tartrate $\left(\mathrm{KNaC}_{4} \mathrm{H}_{4} \mathrm{O}_{6} \cdot 4 \mathrm{H}_{2} \mathrm{O}\right)$, and $37 \%$ formaldehyde $\left(\mathrm{CH}_{2} \mathrm{O}\right)$. In order to facilitate the coating process of the $\mathrm{SiC}$ particles they must be activated firstly. The applied activation consisted of distilled water, hydrochloric acid $(\mathrm{HCl})$, and palladium chloride $\left(\mathrm{PdCl}_{2}\right)$. All the components of the activation and coating solutions were provided by Chemical Company SA, Iasi, Romania.

\subsection{Equipment}

All components were weighed with a RADWAG AS 60/220.X2 (Radom, Poland) analytical balance.

The chemical analysis of the base alloy was performed with a Spectromax (Kleve, Germany) XF-BT spectrometer.

The activation of $\mathrm{SiC}$ particles was achieved by mixing them in the activating solution in a IKA C-MAG HS 7 (IKA-Werke GmbH \& Co. KG, Staufen im Breisgau, Germany) magnetic stirrer with heating and ceramic heating plate, which offers excellent chemical resistance.

The calcination was performed in an electric oven with resistors, UTTIS Romania type (București, Romania), model CE4×2x1 with $3.5 \mathrm{~kW}$ power.

The alloy was melted in a laboratory size electric oven with resistors. The centrifugal casting was performed on a vertical axis casting plant, with installation also located in the laboratories of Materials Science Department and presented in Figure 1. 


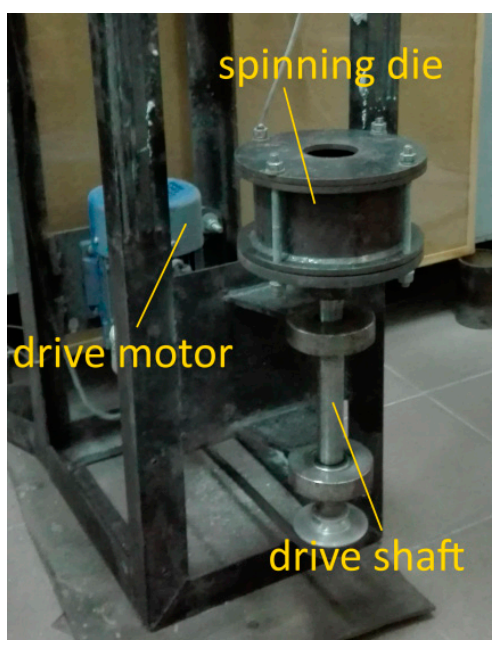

(a)

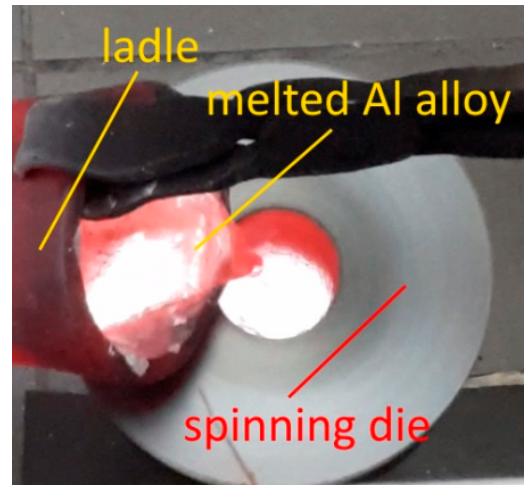

(b)

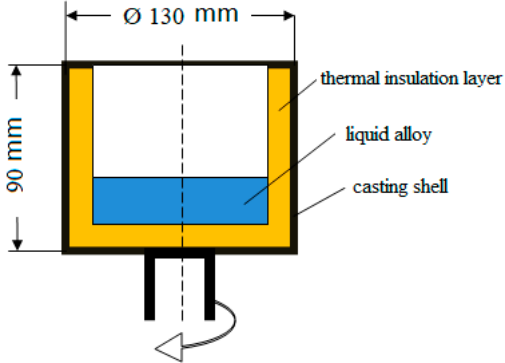

(c)

Figure 1. Centrifugal casting installation, with vertical rotation axis. (a) Experimental device, (b) casting process, (c) casting shell design.

The shell was coated with a thermoreactive binder (20 $\mathrm{mm}$ thickness) in order to decrease the intensity of the thermal exchange with the environment, keeping the liquid alloy as long as possible in the liquid state in order to intensify the embedding process of the $\mathrm{SiC}$ particles.

Structural analysis was performed using an Omnimet-Buehler analysis system equipped with a Nikon microscope (1000× maximum magnification) and software programs suitable for quantitative structural analysis.

The X-ray diffraction patterns were recorded on a Bruker (Billerica, MA, USA) AXS D8 discover XRD (X-ray Diffraction) using a monochromatic $\mathrm{Al}_{\mathrm{K} \alpha}$ X-ray source to identify the phases and constituents.

The samples were also analyzed with a scanning electron microscope (SEM, Quanta FEI, Eindhoven, The Netherlands) equipped with an X-ray energy dispersion spectroscopy system (X-EDS, INCA Oxford Instruments, Abingdon, UK).

The dilatometric analysis was performed on a DIL LINSEIS L75 Platinum Series dilatometer, within $25-550{ }^{\circ} \mathrm{C}$ temperature range deploying $10 \mathrm{~K} \cdot \mathrm{min}^{-1}$ heating rate in the dynamic step [37]. The experimental runs comply with the ASTM E228: 2011 standard procedures. Specimens' dimensions were set as $105 \times 5 \mathrm{~mm}$.

Differential thermal analysis was performed using a NETZCH STA 449 F3 Jupiter (Selb, Germany). NETZCH Proteus-Thermal Analysis-version 5.2.1 software was used for processing the DTA-TG experiment. The DTA peaks were established on the heating curve along with the transformation enthalpy [28,29,38-40].

\subsection{Working Procedure}

The main difficulty encountered in the production of composites with metal matrix based on aluminum and $\mathrm{SiC}$ reinforcement is the low wettability of ceramic materials by the metal bath $[41,42]$. There are a number of studies that have shown that the coating of $\mathrm{SiC}$ particles with a metal such as $\mathrm{Si}, \mathrm{Fe}, \mathrm{Mn}$, or $\mathrm{Cu}$ results in a substantial increase of their wettability.

Choh and Oki clearly demonstrate that the addition of metallic $\mathrm{Cu}$ to the surface of $\mathrm{SiC}$ particles considerably increases their wettability by molten aluminum [42].

In the present research, the authors started from the considerations presented above and did not aim to measure the wettability of $\mathrm{SiC}$ particles in aluminum alloy but to demonstrate the applicability and advantages of the method.

The SiC particles were coated with $\mathrm{Cu}$ in order to improve their wettability in the molten alloy metal bath. The coating of the SiC particles with a thin layer of copper was 
performed by a two steps process: Step 1, the activation of the particle surface and step two consisting in the actual coating process. To improve the adhesion of $\mathrm{Cu}$ to $\mathrm{SiC}$ particle's surface they were activated in a solution with the following composition: $500 \mathrm{~mL} \mathrm{H}_{2} \mathrm{O}$, $0.5 \mathrm{~mL} \mathrm{HCl}$, and $0.25 \mathrm{~g}$ of $\mathrm{PdCl}_{2}$. The activation process followed these steps:

- $100 \mathrm{~g}$ of $\mathrm{SiC}$ particles were introduced in the activating solution then mixed with the magnetic stirrer for $30 \mathrm{~min}$;

- $\quad \mathrm{SiC}$ particles were filtered and washed;

- $\quad \mathrm{SiC}$ particles were calcinated at $150{ }^{\circ} \mathrm{C}$ for $40 \mathrm{~min}$ (heated together with the furnace).

After the activation, the particles were submerged for $60 \mathrm{~min}$ (with sample collection after $30 \mathrm{~min}$ ) in a coating solution having the following composition: $2000 \mathrm{~mL}$ distilled $\mathrm{H}_{2} \mathrm{O}, 20 \mathrm{~g} \mathrm{CuSO}_{4}, 20 \mathrm{~g} \mathrm{NaOH}, 100 \mathrm{~g} \mathrm{KNaC}_{4} \mathrm{H}_{4} \mathrm{O}_{6} \cdot 4 \mathrm{H}_{2} \mathrm{O}, 20 \mathrm{~mL} \mathrm{CH} \mathrm{C}_{2} \mathrm{O}$.

An empirical calculus was used to determinate the copper requirement within the coating solution, based on the following simplifying hypotheses:

- All SiC particles were considered perfectly spherical;

- A medium granulation value of $137 \mu \mathrm{m}$ was considered. It should be mentioned that

$\mathrm{SiC}$ powder was supplementary sorted by particles size criteria in order to increase its uniformity;

- $\quad$ An even layer of $\mathrm{Cu}$ of $1 \mu \mathrm{m}$ was considered on the surface of $\mathrm{SiC}$ particles.

Based on these simplifying hypotheses and taking into account that $25 \mathrm{~g} \mathrm{SiC}$ charges were used, the result was a need of $8 \mathrm{~g}$ of $\mathrm{CuSO}_{4}$.

In order to have the safety of a sufficient content of $\mathrm{Cu}$ in the coating bath, the presented composition was reached (containing 2.5 times more $\mathrm{CuSO}_{4}$ than the calculated minimum necessary).

The working parameters for both activation and coating stages are presented in Table 2.

Table 2. Working parameters.

\begin{tabular}{ccccccc}
\hline & Solution/SiC & SiC, $\mathbf{g}$ & $\begin{array}{c}\text { Cu Quantity in } \\
\text { Solution, }\end{array}$ & Mixing Time, min & Samples Codes & Observations \\
\hline $\begin{array}{c}\text { Activating } \\
\text { solution }\end{array}$ & 5.0075 & 100 & & 30 & $\begin{array}{c}\text { Mixing } \\
\text { Filtration, washing } \\
\text { Calcination at } 50{ }^{\circ} \text { C, } \\
40 \text { min }\end{array}$ \\
\hline & & & & & 30 & VIa30 \\
Coating & 21.6 & 25 & 8 & 60 & VIa60 \\
solution & 21.6 & 25 & 8 & 30 & VIb30 \\
& 86.4 & 12.5 & 8 & 60 & VIb60 \\
& 172.8 & 12.5 & 8 & 30 & VIc30 \\
\end{tabular}

For the embedment of the $\mathrm{SiC}$ particles into the aluminum alloy metallic base, three different variants of the centrifugal casting process with vertical rotation axis were used:

$\mathrm{V}_{1}$ - The alloy overheated at $850{ }^{\circ} \mathrm{C}$ was poured in the resting (nonrotating) shell. Afterwards, the $\mathrm{Cu}$-coated $\mathrm{SiC}$ particles were introduced and preheated to $900^{\circ} \mathrm{C}$. Then the shell was rotated with $1500 \mathrm{rpm}$ speed. It should be mentioned that after the solidification of the composite sample it was found that during the pre-heating stage the agglomeration of $\mathrm{SiC}$ particles occurred.

$\mathrm{V}_{2}$-followed the same steps as the first version but this time the agglomerations of particles were crushed and only afterwards introduced in the shell.

$\mathrm{V}_{3}$-room temperature uncoated $\mathrm{SiC}$ particles were introduced into the resting shell, which was afterwards rotated with $1500 \mathrm{rpm}$ until solidification of the alloy. The casting of the aluminum alloy was done while the shell was rotating.

The resulted muff shaped composites (Øext $=110 / \varnothing i n t=90 \times 80 \mathrm{~mm}$ ) were cut into samples that were further tested in terms of their structural and thermal properties. The 
XRD patterns were obtained from $\mathrm{Cu}$-coated $\mathrm{SiC}$ particles in order to prove the coating existence on the particles.

To facilitate the analysis of the samples they were embedded in epoxydic resin and the surface was metallographically processed to be observed under the microscope. The structural analysis was not the main objective of this characterization, but the embedment characteristics was.

Differential thermal analysis was performed under protective argon atmosphere (argon flow $20 \mathrm{~mL} / \mathrm{min}$ ) with a heating/cooling rate of $10^{\circ} \mathrm{C} \cdot \mathrm{min}^{-1}$. Dilatometric analysis was performed in air with $10^{\circ} \mathrm{C} \cdot \mathrm{min}^{-1}$ heating rate.

\section{Results and Dissscussion}

\subsection{XRD}

The X-ray diffraction patterns of the Cu-coated $\mathrm{SiC}$ particles, for two different durations of the coating stage, are presented in Figure 2.

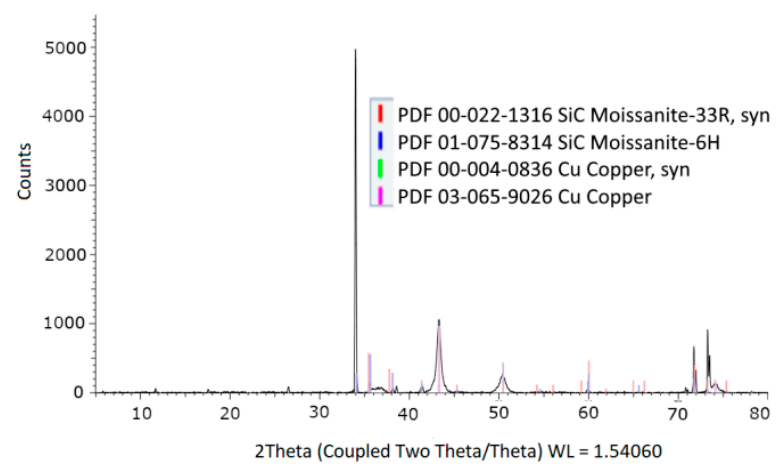

(a)

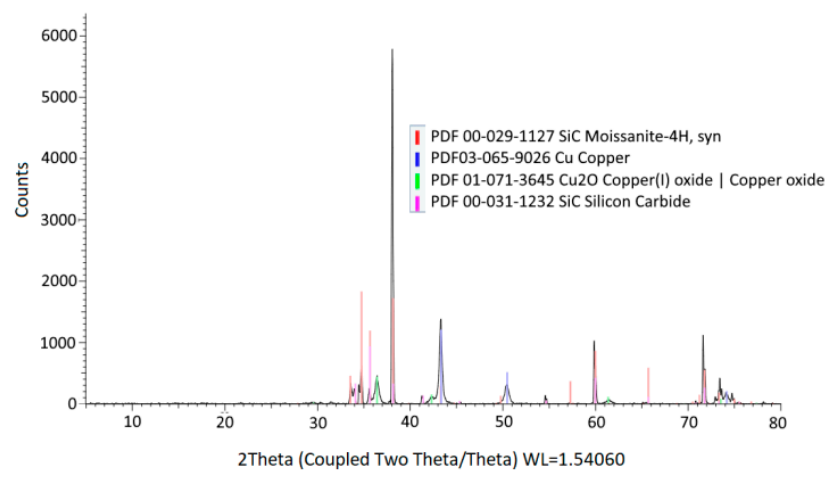

(b)

Figure 2. Composite's structural arrangement. (a) 30 min coating time, (b) 60 min coating time.

At a first look at the XRD patterns depicted in Figure 2 one can observe that the $\mathrm{Cu}$ phase appears at multiple angular positions after the 60 min coating time when compared to the 30 min coating time pattern. This can suggest that together with the growth of the coating time, the $\mathrm{Cu}$ quantity also increases, as expected. This aspect can be translated into a better wettability of the $\mathrm{SiC}$ particles in the aluminum alloy.

Although it is expected that part of the metallic coating will be detached from the ceramic particles, according to the research results shown in Figure 3 it is found that the $\mathrm{Cu}$ film remains attached to the $\mathrm{SiC}$ particle, its role being to help integrate more of the $\mathrm{SiC}$ particle in the aluminum metal mass. SEM analyzes were performed on the presented sample, which also demonstrates the presence of copper on the surface of the $\mathrm{SiC}$ particleFigure 3 and Table 3. The presence of pores and microcracks at the $\mathrm{Al}$ alloy-SiC interface is a result of the surface preparation process of the metallographic sample.

Table 3. Results of EDS analysis on the studied material.

\begin{tabular}{cccc}
\hline Element Line & Net Counts & Weight, $\%$ & Atom, $\mathbf{\%}$ \\
\hline C K & 292 & 10.01 & 18.82 \\
O K & 1017 & 12.69 & 17.90 \\
Al $K$ & 9203 & 50.56 & 42.31 \\
Si K & 3337 & 25.56 & 20.55 \\
Cu L & 95 & 1.18 & 0.42 \\
\hline Total & & 100.00 & 100.00 \\
\hline
\end{tabular}




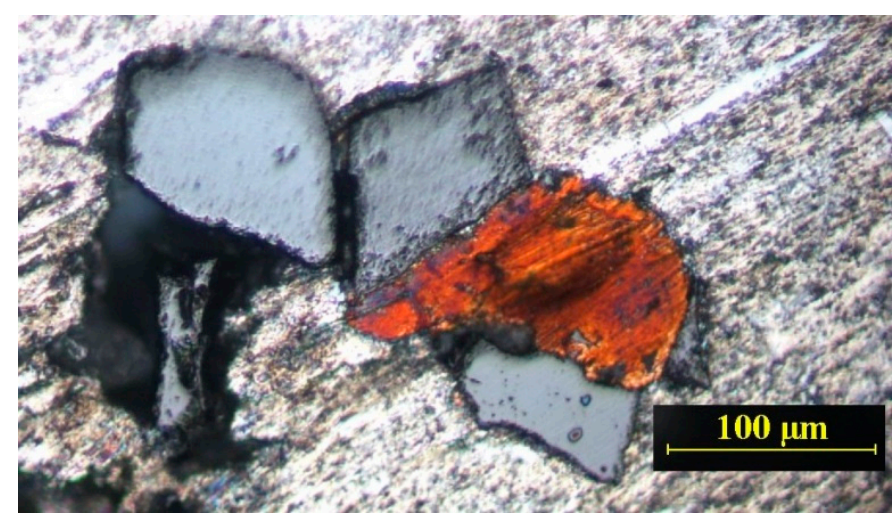

(a)

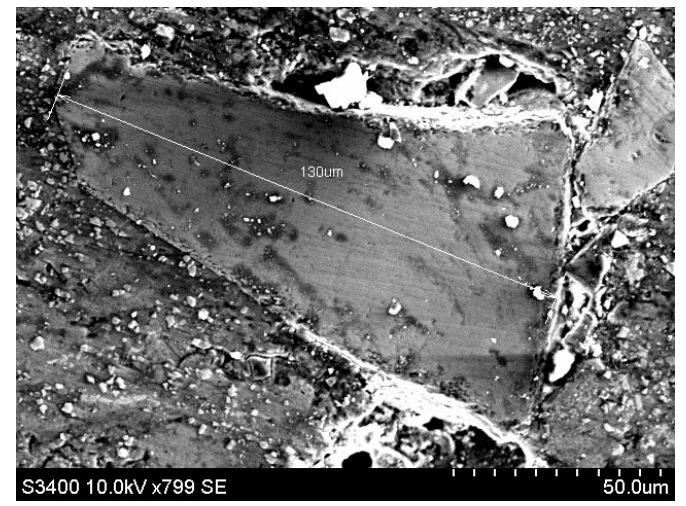

(b)

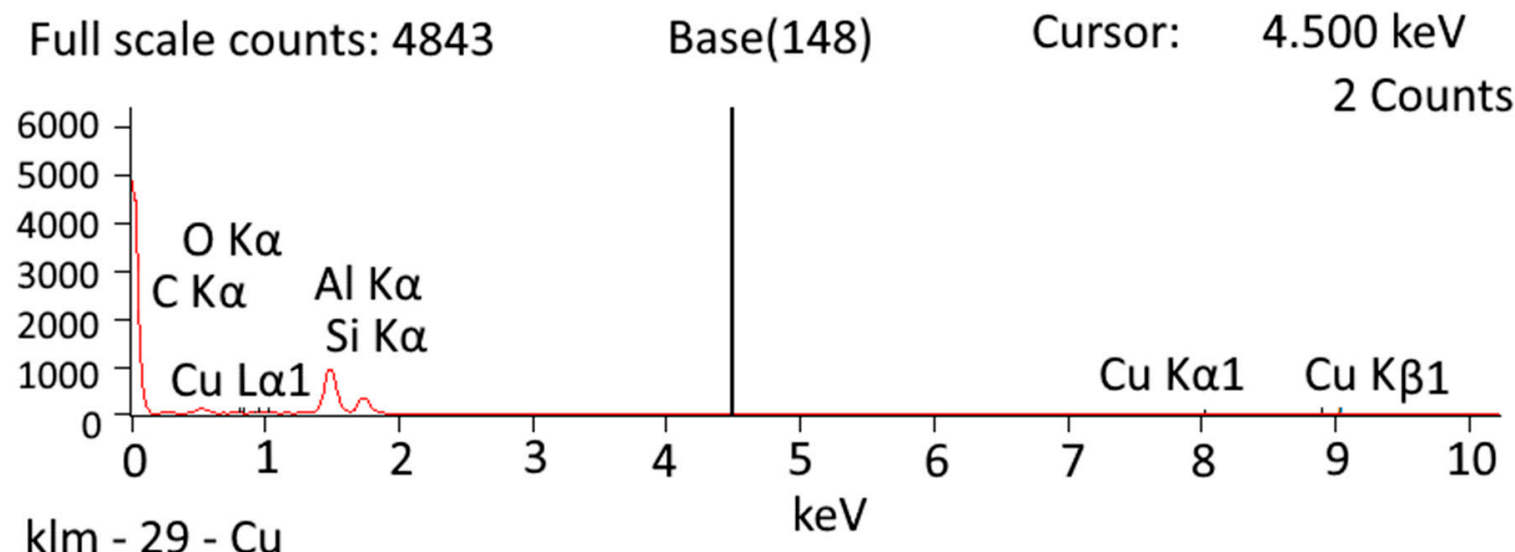

(c)

Figure 3. Presence of copper on the surface of the SiC particle observed. (a) By optical microscope, (b) by SEM analysis, (c) by EDS.

\subsection{Morphological Analysis}

Morphological analysis highlights how the $\mathrm{SiC}$ particles were actually embedded in the aluminum alloy metallic base, for each research variant. It is worth mentioning that the first two variants $\left(\mathrm{V}_{1}, \mathrm{~V}_{2}\right)$ both individual $\mathrm{SiC}$ particles and $\mathrm{SiC}$ agglomerations were concentrated in the interior surface of the casted muffs. This phenomenon is rather unexpected. Due to the formation of $\mathrm{SiC}$ agglomerations air bubbles appear in their rear. This fact leads to the decrease of the density of the agglomerations below the density of the alloy thus resulting in its displacement inwards. The density ratio for the liquid alloy and $\mathrm{SiC}$ particles (2.6/3.1) is in favor of concentrating the silicon carbide on the outer surface of the cylindrical samples. This behavior of the $\mathrm{SiC}$ particles was confirmed only in the case of the composite bush molded in the third process $\left(\mathrm{V}_{3}\right)$.

The corresponding metallographic images for each analyzed variant are presented as follows: $\mathrm{V}_{1}$-Figure $4 ; \mathrm{V}_{2}-$ Figure $5 ; \mathrm{V}_{3}$-Figure 6 . 


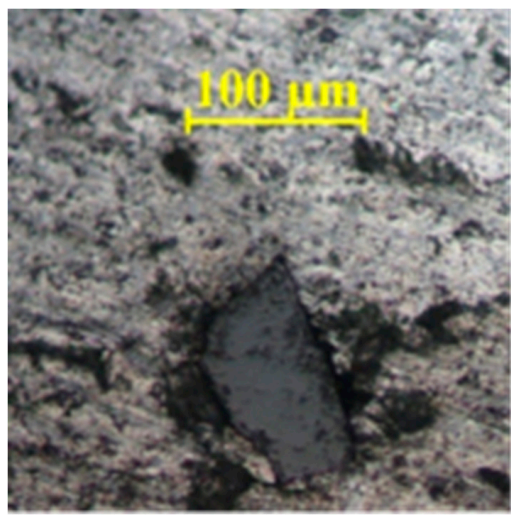

(a)

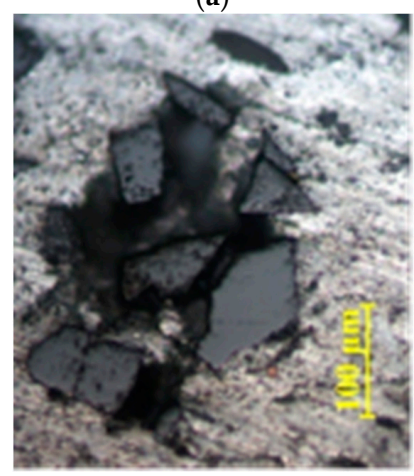

(c)

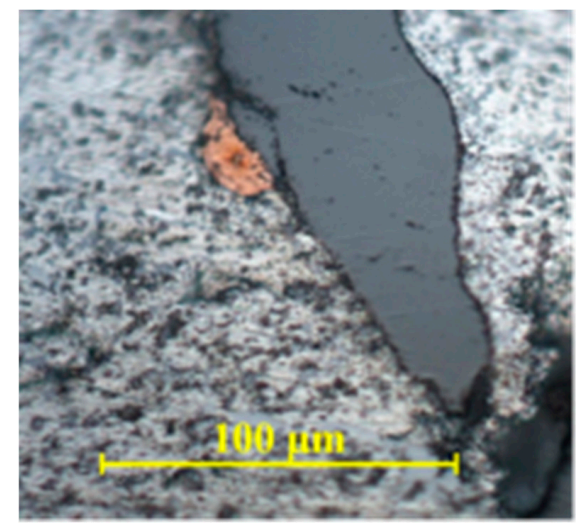

(b)

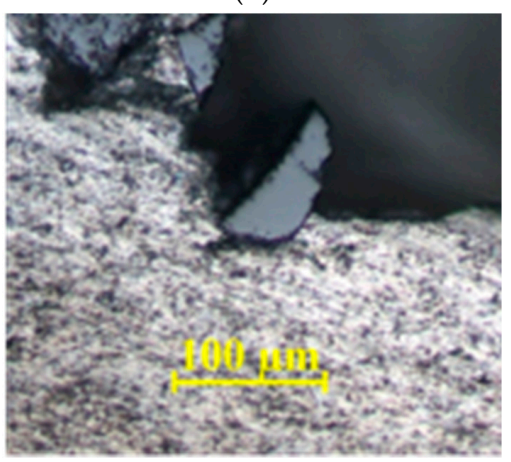

(d)

Figure 4. SiC particles distribution within the metallic base alloy $-\mathrm{V}_{1}$. (a) Central embedded $\mathrm{SiC}$ particle $(\times 200),(\mathbf{b}) \mathrm{Cu}$ on a SiC particle $(\times 500)$, (c) $\mathrm{SiC}$ particles agglomeration $(\times 200),(\mathbf{d}) \mathrm{SiC}$ particles agglomeration $(\times 200)$.

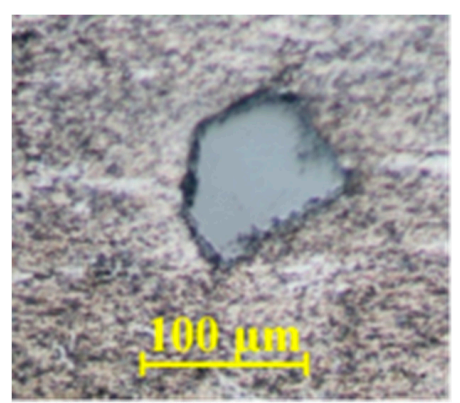

(a)

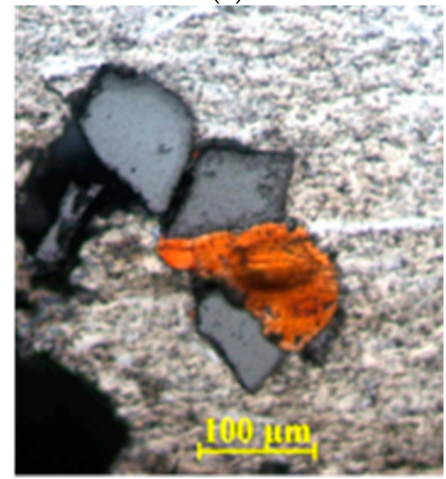

(c)

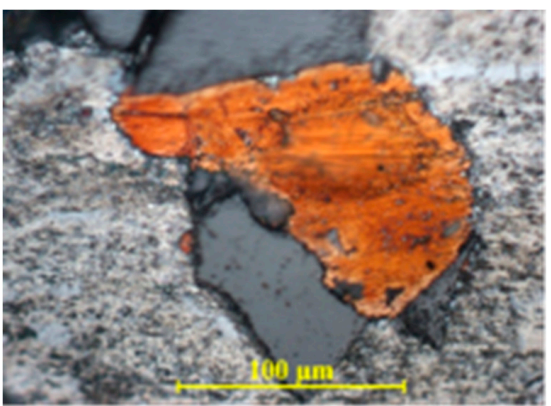

(b)

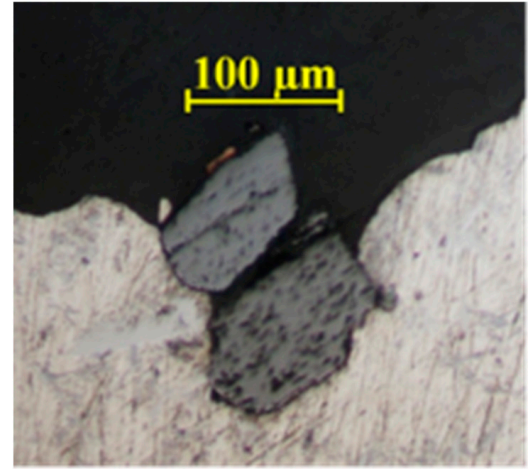

(d)

Figure 5. $\mathrm{SiC}$ distribution in the metallic base $-\mathrm{V}_{2}$. (a) Central embedded SiC particle $(\times 200)$, (b) $\mathrm{Cu}$ on a SiC particle $(\times 500)$, (c) $\mathrm{SiC}$ particles agglomeration $(\times 200)$, (d) SiC particle embedded at sample surface $(\times 200)$. 


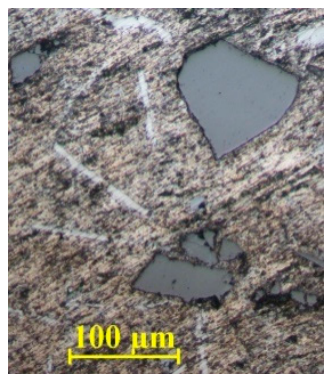

(a)

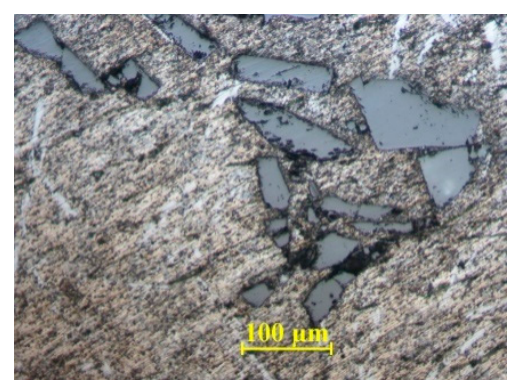

(b)

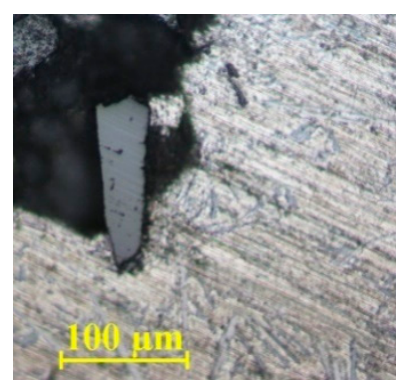

(c)

Figure 6. $\mathrm{SiC}$ distribution in the metallic base $-\mathrm{V}_{3}$. (a) Central embedded $\mathrm{SiC}$ particle $(\times 200)$, (b) SiC particles agglomeration $(\times 200)$, (c) SiC particle embedded at sample surface $(\times 200)$.

For the V1 method the $\mathrm{SiC}$ particles coated with a thin layer of $\mathrm{Cu}$ were preheated at $900{ }^{\circ} \mathrm{C}$ and introduced as such in the metallic mass. Due to the preheating stage the particles started to conglomerate and formed lumps that were not crushed afterwards. As a result, the $\mathrm{SiC}$ particles were not evenly distributed. Instead, some agglomerations appear in certain areas of the samples (Figure 4c). As an effect of the centrifugal casting, certain agglomerations were dispersed, thus well-embedded single particles also appear in the sample (Figure 4a). The use of activated particles (covered with a thin layer of $\mathrm{Cu}$ ) is clearly highlighted in Figure $4 \mathrm{~b}$ where the presence of copper is very well observed. The activated $\mathrm{SiC}$ particles show a good adhesion to the metal mass, which is proved by the fact that, although the samples were processed with abrasive paper, the particles were not removed from the surface (Figure 4d).

Within the $\mathrm{V} 2$ variant of the process, the $\mathrm{SiC}$ particles were preheated at $900{ }^{\circ} \mathrm{C}$ and similar to V1 method, lumps appeared as a result of the agglomeration process. In order to avoid having particles agglomerations in the final composite material, the preheated $\mathrm{SiC}$ lumps were crushed, which resulted in a much more uniform dispersion of them in the sample volume, even in the areas with high density of embedded particles (Figure $5 c$ ). The existence of the thin layer of $\mathrm{Cu}$ on the surface of the particles favored their incorporation process in the metal matrix even for single particles (Figure 5a). The use of $\mathrm{SiC}$ particles covered with a consistent layer of $\mathrm{Cu}$ has the effect of an increased embedding in the base metal mass, as it can be observed from Figure 5b. Variant V2 also ensures a good adhesion of the particles to the sample surface even in the situation of a small contact surface (Figure $5 \mathrm{~d}$ ).

For the V3 method, the introduction of $\mathrm{SiC}$ particles was performed at room temperature, without preheating. It can be easily observed that most $\mathrm{SiC}$ particles are uniformly dispersed in the metal mass of aluminum alloy. This is explained by the fact that without the heating stage, as a source of conglomeration processes, the particles remained dispersed. Although this time the particles were not treated, the absence of the $\mathrm{Cu}$ layer on the surface of the particles did not lead to a sharp decrease in their adhesion to the metal matrix. In Figure 6c one can observe that the particle is well embedded in the alloy even if it is inserted on the surface.

\subsection{Dilatometric Analysis}

The results of the dilatometric analysis presented in Figure 7 show a relatively lower dilatation of the composite (alloy with embedded $\mathrm{SiC}$ particles) than of the alloy itself. The variation curves of the coefficient of expansion according to the temperature, obtained by the derivation of the expansion curves, depict a normal allure in the case of the alloy, in the sense that it also highlights the silica exit from the solid supersaturated alpha solution, with the maximum at $300^{\circ} \mathrm{C}$. It is worth mentioning that the alloy used in the experiments was cast in cast iron ingots, which ensures high cooling rates. In the case of the composite (alloy $+\mathrm{SiC}$ particles), the variation curve of the thermal expansion coefficient according to the 
temperature has two particularities, namely the value of the expansion coefficient is lower than in the case of the alloy without $\mathrm{SiC}$ particles and the appearance of the peak oriented downward, at temperature of $200{ }^{\circ} \mathrm{C}$. Both features can be explained by the presence of $\mathrm{SiC}$ particles in the alloy. As it is known, the value of the thermal expansion coefficient for silicon carbide is $4 \times 10^{-6}{ }^{\circ} \mathrm{C}^{-1}$, which explains the decrease of the expansion coefficient value for the composite. The presence of the downward oriented peak may correspond to a dissolution of the silicon, which separated during the solidification on the surface of the inclusions of $\mathrm{SiC}$ (heterogeneous germination), in the alloy.

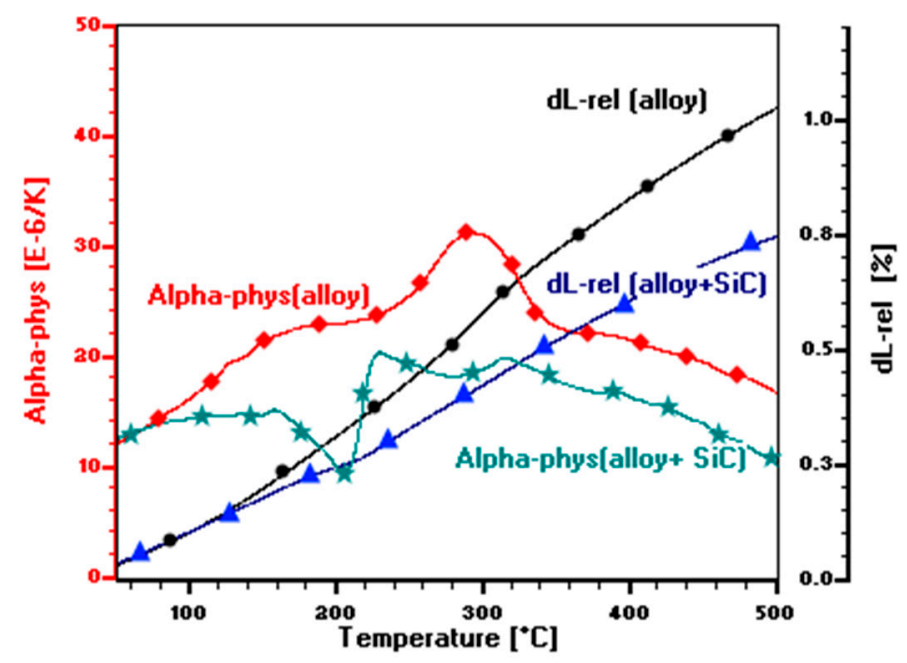

Figure 7. Comparative dilatometric analysis of the alloy and the composite.

\subsection{Thermal Analysis}

The results of the thermal analysis are presented in Figure 8.

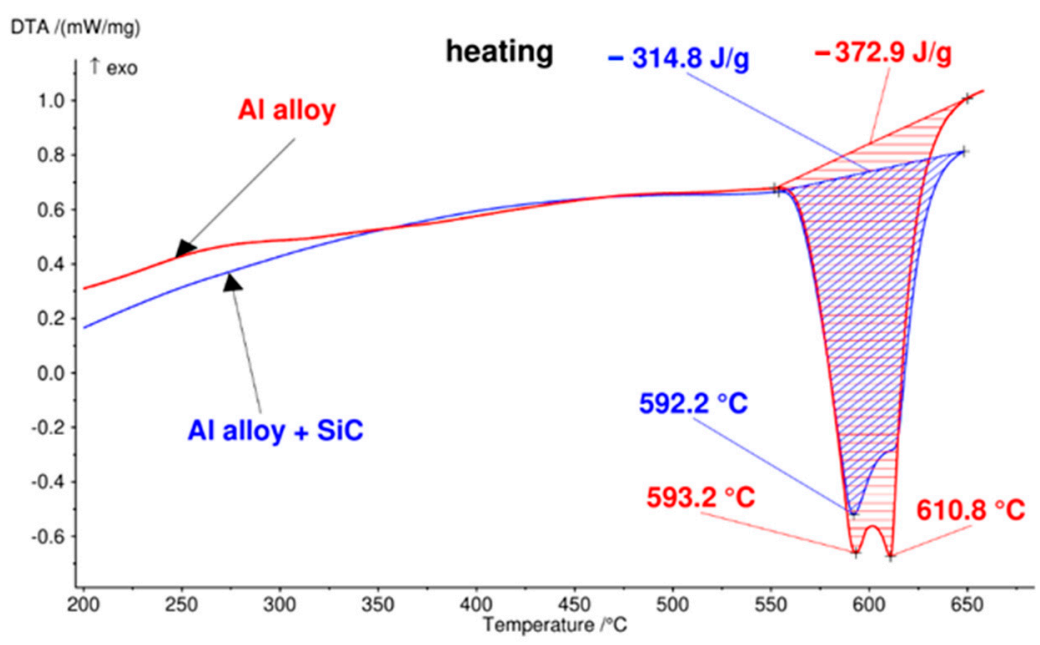

Figure 8. Differential thermal analysis (DTA) curves during heating for aluminum alloy and for the composite aluminum alloy- $\mathrm{SiC}$ particles.

By comparing the DTA curves recorded for the alloy and for the composite, it turns out that in the case of the composite, the value of the melting heat (energy) is lower $\left(314.8 \mathrm{~J} \cdot \mathrm{g}^{-1}\right)$ than in the case of the alloy $\left(372.9 \mathrm{~J} \cdot \mathrm{g}^{-1}\right)$. This difference corresponds to the volume of alloy replaced by the embedded $\mathrm{SiC}$ particles. As it is known, silicon carbide melts at much higher temperatures. 
The metallic coating of SiC particles, in addition to the effect of increasing their wettability by molten metal, also has a role in preventing the formation of aluminum carbide in case of heating above $700{ }^{\circ} \mathrm{C}$.

Hashim et al. [43] reported that a concentration of Si between 7 to $15 \%$ in the alloy prevents the formation of the $\mathrm{Al}_{4} \mathrm{C}_{3}$ phase as a result of the chemical reaction of $\mathrm{Al}$ with $\mathrm{SiC}$ according to chemical relation (1).

$$
4 \mathrm{Al}+3 \mathrm{SiC} \rightarrow \mathrm{Al}_{4} \mathrm{C}_{3}+3 \mathrm{Si}
$$

If this reaction takes place extensively, the formation of the $\mathrm{Al}_{4} \mathrm{C}_{3}$ compound leads to a degradation of the composite properties (for example its strength decreases due to the formation of weak phases at the interface).

To confirm this fact, the thermal analysis was performed up to $800{ }^{\circ} \mathrm{C}$ (Figure 9). It can be easily noticed on the DTA curve that during heating no transformations occur after the aluminum melts, which means that the metal coating protects the reinforcement particles during the heating process.

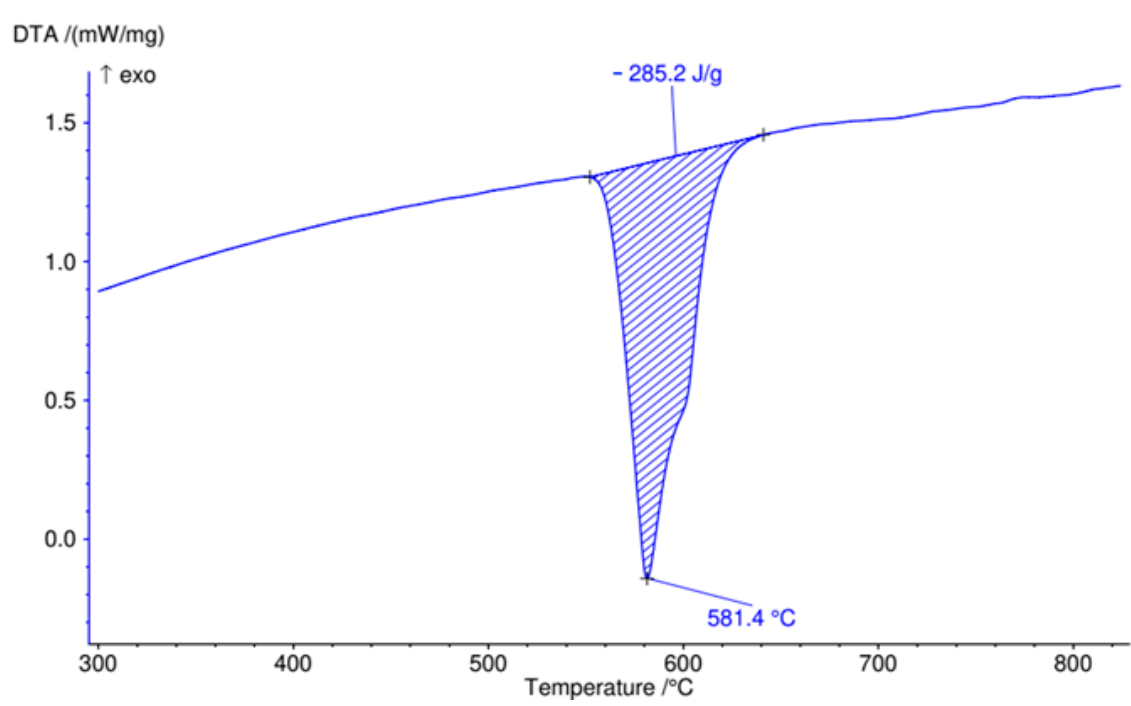

Figure 9. Differential thermal analysis (DTA) heating curve up to $800^{\circ} \mathrm{C}$ for the composite aluminum alloy-SiC particles.

\section{Conclusions}

The present research focused on the incorporation conditions of SiC particles by the liquid alloy by covering them with $\mathrm{Cu}$ (element which is moistened by the liquid alloy) under the conditions of centrifugation process.

The authors show that by combining centrifugal casting with coating of SiC particles with a thin layer of $\mathrm{Cu}$, one can successfully obtain Al-SiC composite alloys with a uniform distribution of the reinforcer in the metal matrix.

When producing these composites, greater attention should be paid to avoiding the agglomeration of SiC particles. A drawback needs to be solved, namely the impossibility to achieve a homogeneous/uniform distribution of SiC particles in the base metal mass.

It was found that the results obtained by the DTA analysis are consistent with those obtained by the DIL method and thus the presence of SiC particles in the volume of the alloy is confirmed. At the same time, the structural observations under the optical microscope observed at the surface of the samples, are also confirmed by the DTA and DIL analyzes carried out in the volume of the samples.

Another novelty highlighted by the present research shows that by adjusting the proportion of $\mathrm{SiC}$ in the composite, it is possible to classify the value of the coefficient of thermal expansion within desired limits. 
Author Contributions: Conceptualization, B.V., I.M., and T.B.; methodology, B.V., T.B., and I.M.; investigation, B.V., I.M., T.B., D.M., M.A.P., M.C., C.G., and D.C.; writing-original draft preparation, T.B., B.V., C.G., and I.M.; writing-review and editing, C.G., D.M., M.C., D.C., and M.A.P.; supervision, B.V., I.M., and T.B.; project administration, I.M., B.V., and T.B. All authors have read and agreed to the published version of the manuscript.

Funding: This research received no external funding.

Institutional Review Board Statement: Not applicable.

Informed Consent Statement: Not applicable.

Acknowledgments: We hereby acknowledge the structural funds project PRO-DD (POS-CCE, O.2.2.1., ID 123, SMIS 2637, contract no. 11/2009) for providing the infrastructure used in this paper.

Conflicts of Interest: The authors declare no conflict of interest.

\section{References}

1. Sobczak, J.; Drenchev, L. Metallic functionally graded materials: A specific class of advanced composites. J. Mater. Sci. Technol. 2013, 29, 297-316. [CrossRef]

2. Gao, J.; Wang, C. Modeling the solidification of functionally graded materials by centrifugal casting. Mater. Sci. Eng. 2000, 292, 207-215. [CrossRef]

3. Velhinho, A.; Sequeira, P. Al/SiCp functionally graded metalmatrix composites produced by centrifugal casting: Effect of particle grain size on reinforcement distribution. Mater. Sci. Forum. 2003, 423, 257-262. [CrossRef]

4. Babu, P.E.J.; Rajan, T.P.D.; Savithri, S.; Pillai, U.T.S.; Pai, B.C. Theoretical Analysis and Computer Simulation of the Particle Gradient Distribution in a Centrifugally Cast Functionally Gradient Materials. In Proceedings of the International Symposium of Research Students on Materials Science and Engineering, Chennai, India, 20-22 December 2004.

5. Rahimi, G.H.; Nejad, M.Z. Deformations and stresses in rotating FGM pressurized thick hollow tube under thermal load. Sci. Res. Essay 2009, 4, 131-140.

6. Abdul Samad, P.; Sandeep, K. Mathematical modeling and computer simulation of particle gradient distribution in a vertical centrifugally cast functionally gradient composite. Int. J. Innov. Res. Sci. Eng. Technol. 2014, 3, 441-447.

7. Zhou, W.; Zhou, H.; Zhang, R.; Pei, Y.; Fang, D. Measuring residual stress and its influence on properties of porous $\mathrm{ZrO}_{2} /\left(\mathrm{ZrO}_{2}+\right.$ Ni) ceramics. Mater. Sci. Eng. A. 2015, 622, 82-90. [CrossRef]

8. Zhou, W.; Zhang, R.; Ai, S.; Pei, Y.; Fang, D. Analytical modeling of thermal residual stresses and optimal design of $\mathrm{ZrO}_{2} /\left(\mathrm{ZrO}_{2}+\mathrm{Ni}\right)$ sandwich ceramics. Ceram. Int. 2015, 41, 8142-8148. [CrossRef]

9. Markandan, K.; Lim, R.; Kanaujia, P.K.; bin Mohd Rosdi, M.R.; Tey, Z.H.; Goh, J.S.; Lam, Y.C.; Lai, C. Additive manufacturing of composite materials and functionally graded structures using selective heat melting technique. J. Mater. Sci. Technol. 2020, 47, 243-252. [CrossRef]

10. Yan, L.; Chen, Y.; Liou, F. Additive manufacturing of functionally graded metallic materials using laser metal deposition. Addit. Manuf. 2020, 31. [CrossRef]

11. Zhou, W.; Ai, S.; Chen, M.; Zhang, R.; He, R.; Pei, Y.; Fang, D. Preparation and thermodynamic analysis of the porous $\mathrm{ZrO}_{2} /\left(\mathrm{ZrO}_{2}\right.$ $+\mathrm{Ni}$ ) functionally graded bolted joint. Compos. Part B 2015, 82, 13-22. [CrossRef]

12. Zhou, W.; Zhang, R.; Ai, S.; He, R.; Pei, Y.; Fang, D. Load distribution in threads of porous metal-ceramic functionally graded composite joints subjected to thermomechanical loading. Compos. Struct. 2015, 134, 680-688. [CrossRef]

13. Zhou, W.; Zhang, R.; Fang, D. Design and analysis of the porous $\mathrm{ZrO}_{2} /\left(\mathrm{ZrO}_{2}+\mathrm{Ni}\right)$ ceramic joint with load bearing-heat insulation integration. Ceram. Int. 2016, 42, 1416-1424. [CrossRef]

14. Tomolya, K.; Gacsi, Z.; Kovacs, A. Copper coating by electroless process for aluminium matrix composite. Mater. Sci. Forum 2005, 473-474, 159-164. [CrossRef]

15. Davidson, A.M.; Regener, D. A comparation of aluminium-based metal-matrix composites reinforced with coated and uncoated particulate silicon carbide. Compos. Sci. Technol. 2000, 60, 865-869. [CrossRef]

16. Xue, C.; Bai, H.; Tao, P.F.; Wang, J.W.; Jiang, N.; Wang, S.L. Thermal conductivity and mechanical properties of flake graphite/Al composite with a SiC nano-layer on graphite surface. Mater. Des. 2016, 108, 250-258. [CrossRef]

17. Carvalho, O.; Buciumeanu, M.; Madeira, S.; Soares, D.; Silva, F.S.; Miranda, G. Mechanisms governing the mechanical behaviour of an AlSi-CNTs-SiCp hybrid composite. Compos. Part B 2016, 90, 443-449. [CrossRef]

18. Narciso, J.; Molina, J.M.; Rodriguez, A.; Rodriguez-Reinoso, F.; Louis, E. Effects of infiltration pressure on mechanical properties of Al-12Si/graphite composites for piston engines. Compos. Part B Eng. 2016, 91, 441-447. [CrossRef]

19. Rajaram, G.; Kumaran, S.; Suwas, S. Effect of strain rate on tensile and compression behaviour of Al-Si/graphite composite. Mater. Sci. Eng. A 2011, 528, 6271-6278. [CrossRef]

20. Goto, H.; Uchijo, K. Wear mechanism of Al-Si Alloy impregnated graphite composites under dry sliding. Wear 2005, 259, 613-619. [CrossRef] 
21. Shanmughasundaram, P.; Subramanian, R. Study of parametric optimization of burr formation in step drilling of eutectic Al-Si alloy-Gr composites. J. Mater. Res. Technol. 2014, 3, 150-157. [CrossRef]

22. Madeira, S.; Carvalho, O.; Carneir, V.H.; Soares, D.; Silva, F.S.; Miranda, G. Damping capacity and dynamic modulus of hot pressed AlSi composites reinforced with different SiC particle sized. Compos. Part B 2016, 90, 399-405. [CrossRef]

23. Huang, Y.; Gu, J.; You, S.; Ulrich, K.K.; Hort, N. Grain refinements of magnesium alloys inoculated by additions of external SiC particles. IOP Conf. Ser.: Mater. Sci. Eng. 2019, 529, 1-6. [CrossRef]

24. Milosan, I.; Varga, B.; Bedo, T.; Pop, M.A.; Balat-Pichelin, M.; Luca-Motoc, D.; Stoicanescu, M. Thermal processing and analysis of AlSi12-SiC hybrid composites sintered. J. Therm. Anal. Calorim. 2019, 138, 2937-2944. [CrossRef]

25. Pall, M.K.; Vikram, A.; Bajaj, V. Enhanced microstructure and mechanical properties of SiC particle reinforced aluminium alloy composite materials. Acta Metall. Slov. 2019, 25, 253-258. [CrossRef]

26. Cheng, D.H.; Xu, W.Y.; Zhang, Z.Y.; Yiao, Z.H. Electroless copper plating using hypophosphite as reducing agent. Metal Finish. 1997, 95, 34-37. [CrossRef]

27. Deckert, C.A. Electroless copper plating. ASM Handbook Volume V: Surface Engineering; ASM International: Novelty, OH, USA, 1994; pp. 311-322.

28. Brodarac, Z.Z.; Grgurić, T.H.; Burja, J. Thermodynamic stability of AlSi11 alloy microconstituents. J. Therm. Anal. Calorim. 2017, 127, 431-438. [CrossRef]

29. Farahany, S.; Ourdjini, A.; Idris, M.H. The usage of computer-aided cooling curve thermal analysis to optimise eutectic refiner and modifier in Al-Si alloys. J. Therm. Anal. Calorim. 2012, 109, 105-111. [CrossRef]

30. Alpas, A.T.; Zhang, J. Effect of SiC particulate reinforcement on the dry sliding wear of aluminium-silicon alloys (A356). Wear 1993, 155, 81-104. [CrossRef]

31. Balek, V.; Zeleňák, V.; Mitsuhashi, T.; Bakardjieva, S.; Šubrt, J.; Haneda, H. Emanation thermal analysis of SiC based materials. J. Therm. Anal. Calorim. 2002, 67, 83-89. [CrossRef]

32. El-Galy, I.M.; Ahmed, M.H.; Bassiouny, B.I. Characterization of functionally graded Al-SiCp metal matrix composites manufactured by centrifugal casting. Alexandria Eng. J. 2017, 56, 371-381. [CrossRef]

33. Radhika, N.; Raghu, R. Development of functionally graded aluminium composites using centrifugal casting and influence of reinforcements on mechanical and wear properties. Trans. Nonferrous Met. Soc. China 2016, 26, 905-916. [CrossRef]

34. Rajan, T.P.D.; Pillai, R.M.; Pai, B.C. Characterization of centrifugal cast functionally graded aluminum-silicon carbide metal matrix composites. Mater. Charact. 2010, 61, 923-928. [CrossRef]

35. Mohan, A.; Sajikumar, K.S. Fabrication and characterization of centrifugally cast functionally graded A 356-SiCp metal matrix composites. Mater. Today Proc. 2020. [CrossRef]

36. Bikkina, V.; Talasila, S.R.; Adepu, K. Characterization of aluminum based functionally graded composites developed via friction stir processing. Trans. Nonferrous Met. Soc. China 2020, 30, 1743-1755. [CrossRef]

37. Snopiński, P.; Król, M.; Tański, T.; Krupińska, B. Effect of cooling rate on microstructural development in alloy ALMG9. J. Therm. Anal. Calorim. 2018, 133, 379-390. [CrossRef]

38. Gaune-Escard, M. Calorimetric methods. In Molten Salts: From Fundamentals to Applications. NATO Science Series (Series II: Mathematics, Physics, and Chemistry); Gaune-Escard, M., Ed.; Springer: Dordrecht, The Netherlands, 2002; Volume 52. [CrossRef]

39. Labisz, K.; Konieczny, J.; Jurczyk, S.; Tański, T.; Krupiński, M. Thermo-derivate analysis of Al-Si-Cu alloy used for surface treatment. J. Therm. Anal. Calorim. 2017, 129, 895-903. [CrossRef]

40. Mostafapoor, S.; Malekan, M.; Emamy, M. Thermal analysis study on the grain refinement of Al-15Zn-2.5 Mg-2.5Cu alloy. J Therm. Anal Calorim. 2017, 127, 1941-1952. [CrossRef]

41. Moraes, E.E.S.; Graça, M.L.A.; Cairo, C.A.A. Study of Aluminium Alloys Wettability on SiC Preform. In Proceedings of the 17th CBECIMat-Congresso Brasileiro de Engenharia e Ciência dos Materiais, Foz do Iguaçu, Brazil, 15-19 November 2006; pp. 4217-4224.

42. Choh, T.; Oki, T. Wettability of SiC to aluminium and aluminium alloys. Mater. Sci. Technol. 1987, 3, 378-385. [CrossRef]

43. Hashim, J.; Looney, L.; Hashmi, M.S.J. The wettability of SiC particles by molten aluminium alloy. J. Mater. Process. Technol. 2001, 119, 324-328. [CrossRef] 